\title{
Reading Difficulties: What Do We Learn from Young English Language Learners?
}

\author{
Vera Savić \\ University of Kragujevac, Faculty of Education in Jagodina, Serbia \\ verasavic035@gmail.com
}

\section{Introduction}

Research suggests that reading difficulties in English as first (L1) or second language (L2) are rather prominent globally, often affecting negatively learners' self-esteem, motivation, attitudes, confidence, and academic and career prospects negatively (International Reading Association 1999, 2007; Montgomeri, 2007; OECD, 2014; Rasinski, 2013; Westwood, 2008). Although English L2 learners are among the groups that can experience serious failure in reading (Westwood, 2008), there is still limited research in this field, especially in early/beginning reading in English as a foreign language (EFL). Serbia is no exception: since the introduction of English as a compulsory school subject from primary Grade One in 2003, there have been no research studies to verify what can be achieved in early reading skill development, and/or to point to reading difficulties and areas requiring effective action for improving EFL reading (Savić, 2016).

International Reading Association (1999) defines reading as "a complex system of deriving meaning from print" (p. 3), involving motivation to read, strategies to make meaning from print, ability to read fluently and to decode new words, and the knowledge and skills to connect speech sounds to print. Grabe and Stoller (2011) describe the components of reading abilities: lower-level processes and higher-level processes, the former referring to more automatic language processes like lexical access, syntactic parsing and semantic proposition formulation, and the latter describing the process of comprehension and construction of the text and situation model of reader interpretation. Both groups of components of reading abilities are equally difficult to develop (and both of them are aspects of working memory processing), and may be the reasons for reading difficulties: although higher level language skills are important for comprehension, "young children's reading comprehension is strongly predicted by other lower level language skills, such as word reading accuracy and verbal and semantic skills" (Cain, Oakhill \& Bryant, 2004, p. 232). Westwood (2008) argues that struggling readers often cannot use the word recognition strategies rapidly, or are not able to decode words with difficult (irregular) spelling patterns due to poor phonic skills and ineffective decoding strategies. If they try decoding letter-by-letter, they become very slow, thus "overloading their working memory and impairing comprehension" (Westwood, 2008, p. 18). As a consequence, beginning readers often depend on top-down processing and on transfer of L1 reading processes.

What is more, research has shown that two different strategies are used in reading, depending on orthographic depth: sublexical (alphabetic) and lexical (whole word) (Perfetti \& Dunlap, 2008). Perfetti and Dunlap (2008) contend that two 
different types of errors are thus caused: using the lexical strategy in reading "leads readers, when they make errors, to respond with real words based on shared letters or partial visual overlap with the target word, for example, responding 'near' for the word 'never', while the sublexical strategy "leads to errors with high phoneme overlap with the target word, even when that means producing non-words" at the expense of lexicality (Perfetti \& Dunlap, 2008, p. 27). Since Serbian is an alphabetic language with shallow orthography, the tendency to use the sublexical strategy may be more common than the use of the lexical strategy for Serbian readers when reading in Serbian (L1), and may also be transferred to their reading in English (L2). Therefore, the errors that might appear in their reading in English as L2 would result from their tendency to use the same strategy instead of the more appropriate lexical one, i.e. they would probably sound out new words applying the learned letter-sound correspondences, instead of responding with a real word similar to the target one. Moreover, due to the dominant strategy, the reading problems of Serbian beginning readers may involve the rate of reading and accuracy of spelling, rather than phonological awareness or decoding (Perfetti \& Dunlap, 2008).

There may be other negative transfer effects, like the influence of L1 syntactic knowledge, of false cognates and orthographic differences, which may cause reading difficulties with beginning readers, such as pronunciation difficulties, slow reading and inaccurate comprehension (Grabe, 1991). Moreover, if a child possesses poor knowledge of vocabulary, or limited knowledge of the world related to the topic of the text, a child will experience difficulties in making necessary inferences (Oakhill, Cain \& Elbro, 2015). Apart from vocabulary knowledge, syntactic skills of beginning readers may be the cause of reading comprehension difficulties. Although young learners can make inferences, they sometimes do not do it even upon explicit prompting with questions (Oakhill et al., 2015). Based on their own research, Cain, Oakhill, Barns \& Bryant (2001) maintain that inference failure of poor comprehenders may be the result of the readers' difficulty to select the relevant information for inference making, and of their failure to remember the information necessary for making inferences.

More generally, Grabe and Stoller (2011) argue that inefficient operation of lower-level and higher-level comprehension processes is the principal cause of reading difficulties, both with L1 and L2 readers. The reasons may involve text difficulty, inadequate background or linguistic knowledge of the reader, or underdeveloped reading efficiency. The authors explain that in such cases L2 readers may try to translate the text slowly and mechanically in order to understand it, or they may rely on their past experience as a means of comprehending the text. A large number of studies has focused on the importance of bottom-up and top-down processing in L2 reading comprehension (Chamot \& El-Dinary, 1999; Macaro \& Erler, 2008), concluding that less successful readers rely mostly on phonetic decoding or prior knowledge to make wild guesses, while more successful readers make inferences by combining top-down and bottom-up processes, and by using a variety of strategies and their own world knowledge.

Rasinski (2004a, 2004b, 2013) contends that the lack of proficiency in reading fluency is the most frequent reason of reading comprehension difficulty. Reading fluency "refers to accurate and automatic decoding of the words in the text, along with expressive interpretation of the text, to achieve optimal comprehension" (Rasinski, 2004a, p. 2), which emphasizes the significance of accurate and fast decoding, and appropriate expression and phrasing, for achieving fluency. Research has indicated a strong correlation between reading fluency and comprehension, thus highlighting the 
need to include measurements of oral reading fluency in current studies of reading skills development and in assessing the effectiveness of reading and intervention programmes (Fuchs, Fuchs, Hosp \& Jenkins, 2001). Accuracy in word decoding, speed and automaticity in word recognition, expressiveness and prosody are three dimensions of reading fluency that are critical for comprehension (Rasinski, 2004a). Comprehension difficulties appear when these three dimensions are absent from a child's reading (Rasinski 2004a, 2004b). Accuracy in word decoding can be measured by counting the number of words read correctly in a minute; when reading in English, Fifth graders should read approximately 100-125 words correct per minute, and their oral reading errors may fall under several categories of miscues, like mispronunciations, substitutions, reversals, omissions, or teacher prompts (Rasinski, 2004a). These quantitative measures can point to the types of decoding difficulties, the kinds of cueing systems (semantic, syntactic, and graphophonic) readers are applying or fail to apply while reading in L2, and to the use of self-corrections and comprehension monitoring skills (Fuchs at al., 2001; Serafini, 2010). What is more, analysis of miscues gives an insight into the reader's "construction of meaning and the process of comprehension" (Goodman \& Goodman, 1998, p. 107). High-quality miscues and low quality miscues influence comprehension differently: the former are semantically and syntactically acceptable and do not interfere with comprehension (the sentence makes sense), while the latter are not semantically and syntactically acceptable and impede comprehension (Goodman, 1998). Obviously, reading difficulties at word level inevitably negatively affect reading comprehension skills, causing difficulties at text level.

It is indisputable that comprehension is the essence and "the ultimate goal of reading" (Nation, 2005, p. 248). However, when measuring children's comprehension, scores do not tell the researchers much about these processes: reading tests provide information about the product of reading comprehension, rather than about "the processes (or deficiencies in particular processes) that resulted in the child arriving at that particular score" (Oakhill, Cain \& Elbro, 2015, p. 30), or about particular reading difficulties experienced in the reading process. The paper presents the results of a research study that aims to shed more light on reading difficulties of beginning English L2 readers and on the effect reading difficulties have on reading comprehension. The following sections focus on the research study and present its results and suggestions for further investigations in the field.

\section{The study}

\subsection{Aims}

The principal aim of the study was to identify reading difficulties experienced by beginning readers studying English in state school settings in Serbia. More precisely, we defined the following research questions: 1. What difficulties do beginning EFL learners experience in oral reading? Our assumption was that beginning EFL readers would experience decoding difficulties and produce a variety of miscues. 2 . What effect does reading accuracy have on reading comprehension? We assumed that reading accuracy and reading comprehension were interdependent. 3. What difficulties do learners experience in comprehending a text? Our assumption was that beginner EFL readers would fail to use effectively the comprehension monitoring skills in reading. 


\subsection{Methodology}

Mixed-method approach was applied and both quantitative and qualitative data were collected.

\subsection{Participants}

Twelve ( $\mathrm{N}=12,7$ boys and 5 girls) 11-year-old EFL learners were selected from six state primary schools located in five geographically distant cities in Serbia. The learners formed a sub-sample of a larger study of reading skills of young EFL learners in Serbia (Savić, 2014; Savić, 2016). At the time of the survey, the participants had been learning English formally for four full school years (Grades 1-4) and two months (the beginning of Grade 5), and had started EFL literacy development in Grade 3. Regarding the English language study context, the participants shared most of the conditions: they had followed the English curriculum from Grade 1 with two 45-minute lessons a week; they shared Serbian as a common mother tongue and were literate in it; they were taught by specialist English language teachers holding a bachelor's or a master's degree in teaching English as a foreign language, with teaching experience ranging from nine to twenty-five years. According to Grade 4 curriculum prescribed for English by the Ministry of Education of Serbia, literacy related competence objectives involved reading with understanding a short text (up to 50 words) comprising mainly familiar words, phrases and language structures prescribed by the grade curriculum. All the participants in the study had reported top grades in English awarded at the end of Grade 4, which indicated that they had successfully mastered the required literacy skills. The approach applied in sampling was purposeful non-probabilistic sampling (Patton, 2002), and competent grade-level readers were chosen to provide valuable information for deeper understanding of the process of reading in a foreign language and to allow identification of reading difficulties.

\subsection{Instruments}

The principal instrument was a prompted think-aloud protocol interview, comprising the reading text of the Cambridge English Young Learners: Young Learners English Tests: Sample Papers - Flyers, 2013 (see the Appendix). The reading text was on a familiar topic (family picnic), but somewhat above the reading competence level of the participants in order to satisfy the demands for a tool for collecting running records for miscue analysis (Goodman, 1998; Serafini, 2010). Also, the text was new to the readers, it was complete (a three-paragraph narrative text with a beginning, middle, and end), and it was "long and challenging enough to produce sufficient numbers of miscues for patterns to appear" (Goodman \& Goodman, 1998, p. 103). Face-to-face individual interviews with the participants were conducted in L1 in the form of performance-based assessment, involving open-ended questions as prompts. The interview in the original study (Savić, 2014; Savić, 2016) consisted of four parts; the first two parts aimed to determine the participants' attitudes to reading and their background contexts, while in parts three and four the participants' reading fluency and reading difficulties were determined. The results presented here related only to parts three and four, which aimed to elicit the participants' thoughts/cognitive processes going on in the process of reading, as well as the decoding skills used, the cueing systems applied, and the 
reading difficulties experienced. The interviews produced both quantitative (running records) and qualitative data (the participants' answers to open-ended questions).

\subsection{Procedure}

The interviews were carried out face-to-face with individual readers, in regular classes, in quiet premises of the participants' schools. They lasted up to 45 minutes (the regular class period), were audio recorded and later transcribed and analysed. The interview with each participant began with general questions related to a participant's attitudes to and habits of reading, reading in English, and extensive reading. After that the reading task was introduced by the researcher and a participant was invited to look at the picture and try to predict what the story would be about. The participant was then instructed to read the first paragraph aloud, and then his/her comprehension was checked through questions related to the content of the paragraph. After that, the participant was encouraged to express her/his thoughts related to the story and its content, as well as to predict the development of the story in the paragraph that followed. He/She was also encouraged to guess both the meaning and pronunciation of the new words. The same procedure was repeated with the second paragraph, but before the third, the final and the most linguistically challenging paragraph, the participant was instructed to read the paragraph first silently and then aloud. It is important to stress that the participant was never interrupted while reading, nor did he/she receive any assistance with pronunciation or comprehension, or was urged to skip the word/phrase and continue reading when difficulties appeared.

\section{Results and discussion}

\subsection{Types of miscues and reading comprehension}

The types of miscues in oral reading were determined by listening to the recordings made in the interviews and by comparing them to the field notes made by the researcher. Table 1 shows that there were five different miscue types: 1. mispronunciations, producing non-words; 2 . substitutions; 3 . omissions; 4 . insertions; and 5. rereadings.

Table 1. Types of miscues made by the twelve readers

\begin{tabular}{|l|l|}
\hline \multicolumn{1}{|c|}{ Type of miscue } & \multicolumn{1}{|c|}{ Miscue categories } \\
\hline $\begin{array}{l}\text { mispronunciation } \\
\text { (non-words) }\end{array}$ & $\begin{array}{l}\text { - mispronunciation of past tense inflection for regular verbs -ed } \\
\text { as /ed/ in all cases (non-words): called, carried, shouted, looked, } \\
\text { answered. } \\
-\quad \text { mispronunciation of vowel clusters like -ai-, -au-, } \\
\text {-ea-, -ie-, -ou-, when they appear between consonants } \\
\text { (non-words): near, sweaters, couldn't, because, said, brought, } \\
\text { Treasure, course, mouth, found, our. } \\
\text { - mispronunciation of vowels (non-words): her, takes, few, find, } \\
\text { took, other, tell, saw, kind, other, last, carefully, minutes, gave, us. }\end{array}$ \\
\hline
\end{tabular}




\begin{tabular}{|c|c|}
\hline substitution & 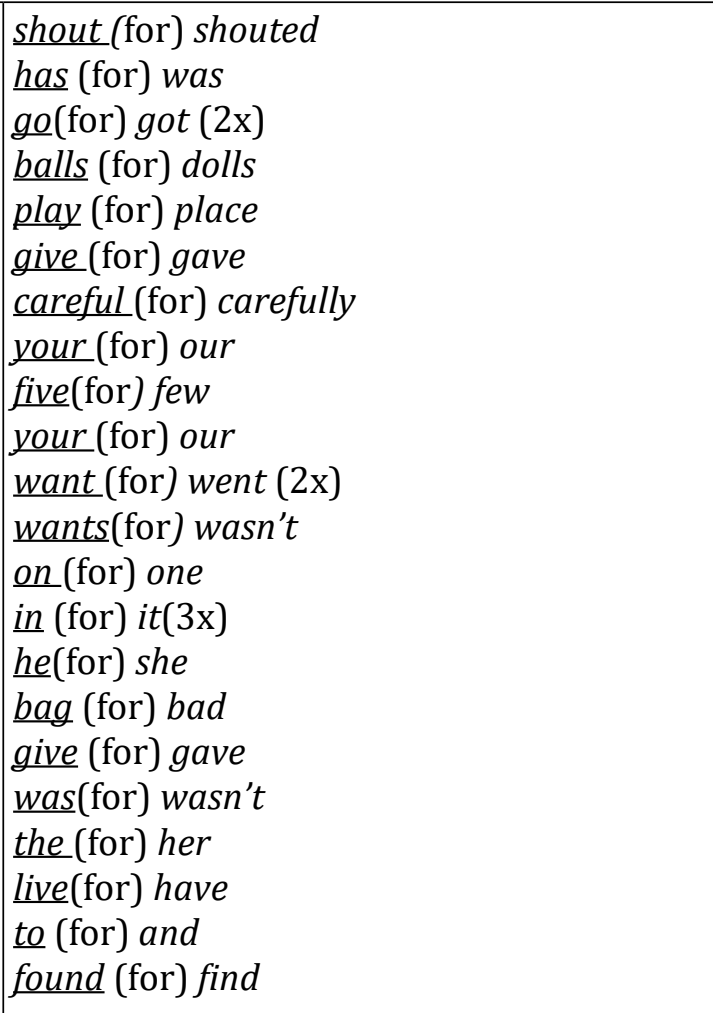 \\
\hline omission & $\begin{array}{l}\text {-omission of the indefinite article: } \underline{a} \text { picnic } \\
\text {-omission of a conjunction: and } \\
\text {-omission of the definite article: the swings }\end{array}$ \\
\hline insertion & $\begin{array}{l}\text { - insertion of a preposition: } \\
\text { to (went to on the swings) (by } 5 \text { readers) } \\
\text { to (to near) } \\
\text { - insertion of an article: } \\
\text { the (to the school) } \\
\text { the (the Emma) (by } 2 \text { readers) } \\
\text { a ( } \text { lots of dolls) } \\
\text { - insertion of an auxiliary verb: } \\
\text { is (the doll is always sits) (by } 2 \text { readers) }\end{array}$ \\
\hline rereading & -repetition of individual words \\
\hline
\end{tabular}

The running records indicate that the participants' pronunciation difficulties mostly involved mispronunciation that produced non-words (observed in 11 out of 12 participants), mostly due to the wrong pronunciation of past tense affixes, irregular paste tense forms, vowels in conjunctions, adjectives, adverbs, and determiners. Another big group of miscues involved substitutions, mainly of verbs (e.g. infinitive for past tense), pronouns (e.g. prepositions were used instead of pronouns, like in instead of $i t$ ), nouns (replaced by phonetically similar nouns, like balls instead of dolls, or play instead of place), and adverbs (adjectives for adverbs, like careful instead of carefully). Omissions included the omissions of articles and conjunctions, while insertions 
involved inserting prepositions and auxiliaries. Some pronunciation difficulties may have resulted from using the sublexical strategy, transferred from L1 reading, by applying the learned letter-sound correspondences (Savić, 2016). This confirms our assumption that the participants would fail to use effectively the comprehension monitoring skills while reading in English, mainly due to the negative transfer of their L1 reading skill.

Although the twelve participants considered themselves to be successful readers, they showed awareness of reading difficulties and were able to describe their own difficulties related to reading in English. The self-reported oral reading difficulties involved pronunciation of new words, pronunciation of some known but difficult words, and pronunciation of inflections. However, these pronunciation problems did not necessarily result in comprehension problems, and mispronunciation did not impede comprehension severely unless it referred to unknown words. Comprehension difficulties were mainly caused by making wrong inferences, by unsuccessful guessing of meanings of new words, and by ineffective use of monitoring strategies. Some examples of unsuccessful guessing included the following words: lake, wrongly understood as 'river'; swings, wrongly understood as 'river bank'; and sweaters wrongly understood as 'small plates' and 'small towels'. Also, wrong inferencing involved attributing the meaning 'swimming' to the unknown word swings, relying both on the context of the story in which the characters were having a picnic near the lake (topdown processing), and on orthography, i.e. the beginning syllable 'swi-' (bottom-up processing) (Savić, 2016). The participants' misinterpretations resulted mainly from their limited knowledge of vocabulary and grammar. Some irregular past tense forms (i.g. took, couldn't, brought, saw) were reported to be new to the participants and therefore very difficult to be interpreted.

Some participants were very good at guessing the meanings of unfamiliar words after being prompted. For example, shouted was a new word for Participant 1 , who managed to guess the meaning after being asked to relate it to the part of the text that immediately preceded this verb (direct speech marked with inverted commas; see the Appendix). Although some participants found it difficult to pronounce regular past tense inflections, they correctly interpreted the past tense verbs (e.g. called, shouted, looked). However, the other participants either failed to guess the meanings of unknown words (e.g lake, sweaters), or were stuck to their misinterpretations, lacking awareness that their guesses were wrong (e.g. swings, was, shouted, sweaters, kind, carefully, brought, saw). When prompted, the participants used their background knowledge and top-down processing skills in interpreting the new vocabulary and grammar.

\subsection{Reading accuracy and reading comprehension}

Table 2 presents the quantitative data related to reading accuracy, determined by taking two measures: the number of miscues was recorded for the participants' reading of the first 100 words, and for the whole text ( 229 words), so that two accuracy rates were calculated. There were two reasons for taking both measures: firstly, there was the difference in difficulty between the two parts of the text, i.e. the first 100 words and the remaining 129 words, the second part being more difficult in terms of unfamiliar vocabulary and unknown grammar; secondly, taking two measures while reading different paragraphs of the same text was considered necessary for increasing validity and reliability of reading proficiency measures. 
Table 2.Reading accuracy levels

\begin{tabular}{|c|c|}
\hline $\begin{array}{l}\text { Participant } \\
\text { (participant's } \\
\text { code) }\end{array}$ & $\begin{array}{c}\text { Reading Accuracy (based on Rasinski, 2004a) } \\
\text { (Independent Level: 97-100\%; Instructional Level: } \\
\text { 90-96\%;Frustration Level: }<90 \% \text { ) }\end{array}$ \\
\hline $\begin{array}{l}\text { Participant } 1 \\
\text { L-1-1-2-13 }\end{array}$ & $\begin{array}{l}\text { Accuracy (first } 100 \text { words): } 98 \% \text { (3 errors: omissions - } 1 \text {, } \\
\text { mispronunciations - } 1 \text {, self corrections - 1) } \\
\text { Total miscues (in } 229 \text { word narrative text): 10; accuracy: } 96 \% \text {; } \\
\text { Level: instructional }\end{array}$ \\
\hline $\begin{array}{l}\text { Participant2 } \\
\text { (L-1-1-1-08) }\end{array}$ & $\begin{array}{l}\text { Accuracy (first } 100 \text { words): 99\% (1 error: substitutions - 1) } \\
\text { Total miscues (in } 229 \text { word narrative text):12; accuracy: 95\%; } \\
\text { Level: instructional }\end{array}$ \\
\hline $\begin{array}{l}\text { Participant } 3 \\
\text { L-2-1-2-03 }\end{array}$ & $\begin{array}{l}\text { Accuracy (first } 100 \text { words): } 94 \% \text { (6 errors: substitutions - } 1 \text {, } \\
\text { mispronunciations - 5) } \\
\text { Total miscues (in } 229 \text { word narrative text): } 20 \text {; accuracy: } 91 \% \text {; } \\
\text { Level: instructional }\end{array}$ \\
\hline $\begin{array}{l}\text { Participant } 4 \\
\text { L-2-1-1-02 }\end{array}$ & $\begin{array}{l}\text { Accuracy (first } 100 \text { words): 99\% (1 error: mispronunciation) } \\
\text { Total miscues (in } 229 \text { word narrative text): 6; accuracy: 97\%; Level: } \\
\text { independent }\end{array}$ \\
\hline $\begin{array}{l}\text { Participant } 5 \\
\text { L-2-2-1-15 }\end{array}$ & $\begin{array}{l}\text { Accuracy (first } 100 \text { words): } 95 \% \text { (5 errors: substitutions - 1, } \\
\text { mispronunciations - 4) } \\
\text { Total miscues (in } 229 \text { word narrative text): } 23 \text {; accuracy: } 90 \% \text {; } \\
\text { Level: instructional }\end{array}$ \\
\hline $\begin{array}{l}\text { Participant } 6 \\
\text { L-3-1-3-16 }\end{array}$ & $\begin{array}{l}\text { Accuracy (first } 100 \text { words): 98\% (2 errors: insertions) } \\
\text { Total miscues (in } 229 \text { word narrative text): 6; accuracy: 97\%; } \\
\text { Level: independent }\end{array}$ \\
\hline $\begin{array}{l}\text { Participant } 7 \\
\text { L-3-1-3-05 }\end{array}$ & $\begin{array}{l}\text { Accuracy (first } 100 \text { words): } 100 \% \\
\text { Total miscues (in } 229 \text { word narrative text): 1; accuracy: 100\%; } \\
\text { Level: independent }\end{array}$ \\
\hline $\begin{array}{l}\text { Participant } 8 \\
\text { L-3-1-3-21 }\end{array}$ & $\begin{array}{l}\text { Accuracy (first } 100 \text { words): } 97 \% \text { (3 errors: insertions - 1, omissions } \\
\text { - 2) } \\
\text { Total miscues (in } 229 \text { word narrative text): 6; accuracy: } 97 \% \text {; } \\
\text { Level: independent }\end{array}$ \\
\hline $\begin{array}{l}\text { Participant } 9 \\
\text { L-4-1-1-09 }\end{array}$ & $\begin{array}{l}\text { Accuracy (first } 100 \text { words): } 92 \% \text { (8 errors: insertions - } 1 \text {, } \\
\text { mispronunciations - 7) } \\
\text { Total miscues (in } 229 \text { word narrative text): } 24 \text {; accuracy: } 90 \% \text {; } \\
\text { Level: instructional }\end{array}$ \\
\hline $\begin{array}{l}\text { Participant } 10 \\
\text { L-4-1-1-10 }\end{array}$ & $\begin{array}{l}\text { Accuracy (first } 100 \text { words): } 91 \% \text { (9 errors: substitutions - 4, } \\
\text { mispronunciations - 5) } \\
\text { Total miscues (in } 229 \text { word narrative text):29; accuracy: } 87 \% \text {; } \\
\text { Level: frustration }\end{array}$ \\
\hline $\begin{array}{l}\text { Participant } 11 \\
\text { L-5-1-2-09 }\end{array}$ & $\begin{array}{l}\text { Accuracy (first } 100 \text { words): } 99 \% \text { ( } 1 \text { error: mispronunciations - 1) } \\
\text { Total miscues (in } 229 \text { word narrative text): 3; accuracy: } 99 \% \text {; } \\
\text { Level: independent }\end{array}$ \\
\hline $\begin{array}{l}\text { Participant } 12 \\
\text { L-5-1-1-27 }\end{array}$ & $\begin{array}{l}\text { Accuracy (first } 100 \text { words): } 95 \% \text { (5 errors: substitutions - } 1 \text {, } \\
\text { insertions - 3, mispronunciations - 1) } \\
\text { Total miscues (in } 229 \text { word narrative text): } 22 \text {; accuracy: } 90 \% \text {; } \\
\text { Level: instructional }\end{array}$ \\
\hline
\end{tabular}


The results showed that the 12 participants' reading involved all three reading accuracy levels, as follows: 5 participants read at the independent level as they were at least $97 \%$ accurate in their oral reading, 6 read at the instructional level as they were at least $90 \%$ accurate in their oral reading, and one was at the frustration level as he or she was less than $90 \%$ accurate in his/her reading (Savić, 2016). There was a difference both in number and quality of miscues among the three levels: the miscues of the participants who read at frustration and instructional levels involved mostly mispronunciation of a large number of known and unfamiliar words (often not recognized as wrong pronunciations), and substitutions that did not fit the context; on the other hand, the participants who read at an independent level mispronounced few known and/or unfamiliar words (managing to guess the meaning of new words), and the insertions they made (mostly prepositions) did not interfere with their understanding of the text. This confirms our assumption that reading comprehension and reading accuracy are interdependent.

\section{Conclusion}

Our study provides significant insight into the development of beginning reading in English as a foreign language. Listening to the participants reading an unfamiliar text in L2 gave valuable data about their development as readers and about reading difficulties they experienced performing the task. Moreover, the prompted thinkaloud protocol yielded significant information related to the participants' background knowledge crucial for understanding the text, to their inference making ability, and the ability to connect ideas in the text and to monitor their own comprehension. Oral reading difficulties recorded and reported in the interviews included mispronunciation of some English phonemes and words, as well as inappropriate reading accuracy. The participants showed metacognitive awareness of the problems they experienced in reading in English as L2, referring to them as their own failure to pronounce new and known words and grammar forms and to interpret them. Still, there were some obvious difficulties that the participants did not recognise or report. Some of these difficulties were related to reading aloud, and were observed in the form of miscues like omissions, repetitions, substitutions, and mispronunciation, which affected the participants' accuracy levels and comprehension. The other difficulties involved making wrong inferences when guessing the meaning of unfamiliar words and grammar forms.

Considering the fact that errors are a necessary part of learning a language, reading difficulties should be seen as components of reading skill development that should be recognised and treated timely and properly. Consequently, development of comprehension monitoring skills and improvement of reading accuracy should be seen as integral parts of teaching beginning reading in English as a foreign language.

\section{References}

Cain, K., Oakhill, J., \& Bryant, P. (2004). Children's reading comprehension ability: Concurrent prediction by working memory, verbal ability, and component skills. Journal of Educational Psychology, 96(1), 31-42. 
Cain, K., Oakhill, J., Barns, M., \& Bryant, P. (2001).Comprehension skill, inferencemaking ability and their relation to knowledge. Memory \& Cognition, 29(6), 850-859. Psychonomic Society, Inc.

Cambridge English Young Learners: Young Learners English Tests: Sample Papers Flyers (2013).

Retrieved February 10, 2013 from: http://www.cambridgeenglish.org/exams/younglearners-english/flyers/preparation/

Chamot, A. U. \& El-Dinary, P. B. (1999). Children's learning strategies in language immersion classrooms. The Modern Language Journal, 83(3) (Autumn, 1999), 319-338. Retrieved March 2, 2013 from: http://www.finchpark.com/courses/ grad-dissert/articles/bilingual/immersion-learning-strategies.pdf

Fuchs, L.S., Fuchs, D., Hosp, M.K., \& Jenkins, J. (2001). Oral reading fluency as an indicator of reading competence: A theoretical, empirical, and historical analysis. Scientific Studies of Reading, 5 (3), 239-256.

Goodman, Y. M. (1998). Miscue analysis for classroom teachers: Some history and some procedures. In C. Weaver (Ed.), Practising what we know: Informed reading instruction (pp.226-236). Urbana: National Council of Teachers of English.

Goodman, Y. M. \& Goodman, K. (1998). To err is human: Learning about language processes by analyzing miscues. Reconsidering a balanced approach to reading (pp. 101-123). Urbana: National Council of Teachers of English.

Grabe, W. (1991). Current developments in second language reading research.TESOL Quarterly, 25(3), 375-406.

Grabe, W., \& Stoller, F. L. (2011).Teaching and researching reading (2 ${ }^{\text {nd }}$ ed.). Great Britain: Pearson Education Limited.

International Reading Association (1999). Using MULTIPLE METHODS of beginning reading instruction: A position statement.Newark: International Reading Association.

International Reading Association (2007). Teaching reading well: A synthesis of the International Reading Association's research on teacher preparation for reading instruction. Retrieved June 16, 2013 from http://www.reading.org/Libraries/ reports-and-standards/teaching_reading_well.pdf

Macaro, E. \& Erler, L. (2008). Raising the achievement of young-beginner readers of French through strategy instruction.Applied Linguistics, 29(1), 90-119.

Montgomery, D. (2007). Spelling, handwriting and dyslexia: Overcoming barriers to learning. Abington: Routledge.

Nation, K. (2005). Children's reading comprehension difficulties. In M. J.Snowling, \& C. Hulme (Eds.), The science of reading: A handbook (pp. 248-266). Oxford: Blackwell Publishing Ltd. doi: 10.1002/9780470757642.ch14

Oakhill, J., Cain, K. \&Elbro, C. (2015): Understanding and teaching reading comprehension (A handbook). London: Routledge.

OECD (2014), PISA 2012 results: What students know and can do - Student performance in mathematics, reading and science (Volume I, Revised edition, February 2014), PISA, OECD Publishing.

Retrieved August 16, 2014 from http://dx.doi.org/10.1787/9789264201118-en.

Patton, M. Q. (2002). Qualitative research and evaluation methods $\left(3^{\text {rd }} \mathrm{ed}\right.$.). Thousand Oaks: Sage Publications.

Perfetti, C. A., \& Dunlap, S. (2008). Learning to read: general principles and writing system variations. In K. Koda, \& A. M. Zehler (Eds.), Learning to read across languages (pp. 13-38). New York: Routledge. 
Rasinski, T. (2004a, reprinted in 2011). Assessing reading fluency. Honolulu: Pacific Resources for Education and Learning.

Rasinski, T. (2004b). Creating fluent readers.Educational Leadership, 61(6), 46-51. Retrieved Feb. 10, 2013 from http://educationalleader.com/subtopicintro/ read/ASCD/ASCD_364_1.pdf

Rasinski, T. (2013). Supportive fluency instruction: The key to reading success (Especially for students who struggle). White Paper. Available at: http:// thefutureinreading.myon.com/sites/default/files/attached/White\%20 Paper\%20-\%20Supportive\%20Fluency\%20Instruction\%20-\%20Dr.\%20 Rasiniski.pdf

Savić, V. (2014). Investigating reading skills of Serbian young learners learning English as a foreign language. In J. Enever et al. (Eds.), Conference proceedings from Early Language Learning: Theory and practice 2014 (pp. 108-114). Umea: Umea University.

Savić, V. (2016). Reading difficulties in English as a foreign language [unpublished doctoral dissertation]Novi Sad: University of Novi Sad.

Serafini, F. (2010).Classroom reading assessments.Classroom reading assessment: more efficient ways to view and evaluate your readers.Portsmouth:Heinemann.

Westwood, P. (2008). What teachers need to know about reading and writing difficulties. Camberwell: Australian Council for Educational Research. 


\section{Appendix: Reading text}

Cambridge English Young Learners: Young Learners English Tests: Sample Papers Flyers (2013).

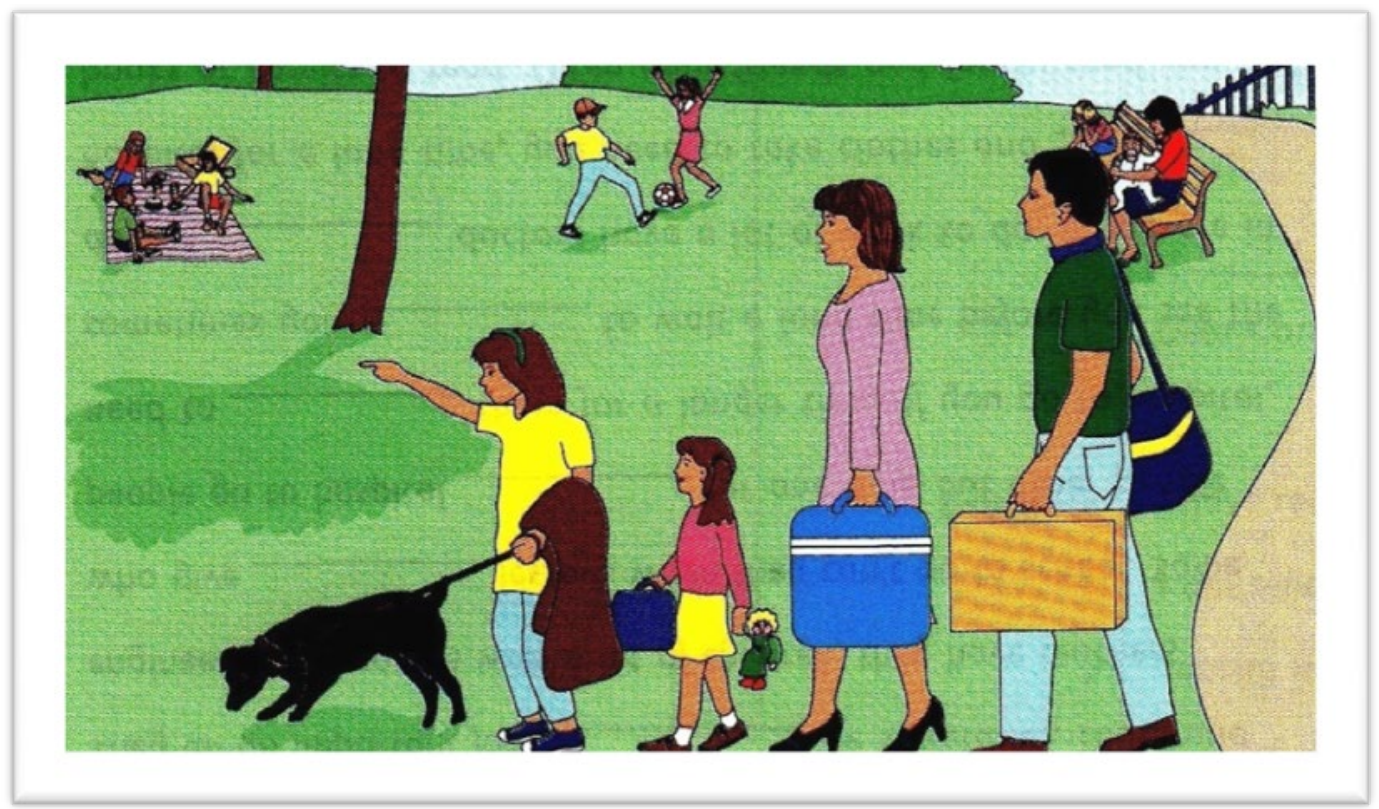

My name is Betty and I have a little sister called Emma. She has lots of dolls, but her favourite one is called Daisy. Mum and Dad gave it to her when she was a baby and she takes it everywhere with her. She takes it to school and to her bedroom and when we sit down to eat, the doll always sits next to Emma.

Last Sunday, our family went to the park to have a picnic. We took our dog, Treasure, with us and of course, Emma took Daisy too. There were a lot of people in the park because it was sunny. We found a place near the lake to have our picnic. After lunch, Emma and I went on the swings. After a few minutes, Emma said to me, "Betty, I want Daisy on the swing with me. Can you go and get her for me?" "OK!" I answered.

But when I went back to our picnic, Daisy wasn't there. "Mum!" I shouted, "we've lost Daisy!" Dad looked in all the bags and Mum and I looked under our sweaters and other things, but we couldn't find her. I went to tell Emma the bad news, but when I got there, I saw Treasure. He carried Daisy carefully in his mouth. "Look!" said Emma, "Treasure has brought Daisy to play with me. He's very kind." 